\title{
Just society
}

\author{
Rakesh K. Sarin ${ }^{1}$
}

Accepted: 2 March 2021 / Published online: 29 April 2021

(C) The Author(s) 2021

\begin{abstract}
I examine the foundations of a just society using the lens of decision theory. The conception of just society is from an individual's viewpoint: where would I rather live if I have an equal chance of being any individual? Three alternative designs for a just society are examined. These are: laissez-faire, maximin and social minimum. Two assumptions about human nature clarify the distinction among three societies. The first assumption is that a representative individual's utility function is concave. The second assumption recognizes that redistribution to achieve equality reduces total wealth. A rational individual would prefer a society where one is free to maximize one's expected utility. A social minimum that includes both the provision of essential human needs and equality of opportunity (education, healthcare, access to capital) for a flourishing life emerges as a candidate solution for the basic structure of society.
\end{abstract}

Keywords Just society · Decisions under uncertainty · Original position · Social minimum $\cdot$ Rawlsian theory $\cdot$ Decisions under ambiguity · Utility theory

\section{Introduction}

Imagine that you do not know your place in society, your income and wealth or your social status. You are to choose a design of society (principles of justice and basic structure) behind a veil of ignorance. As a rational person you are asked to engage in reflective soul searching in the original position (Rawls, 1971, revised edition 1999). The principles of justice determine how the benefits and burdens are shared between members of a society and thus influence the economic and social systems. Your choice in the original position is impartial as you are not able to design principles of

Rakesh K. Sarin

rakesh.sarin@anderson.ucla.edu

1 UCLA Anderson School of Management, 110 Westwood Plaza, Suite B519, Los Angeles, CA 90095, USA 
justice to favor your particular situation. Thus, the principles of justice you choose are fair and the society regulated by these principles is a just society.

Consider for simplicity two states of the world. In one state you are at a more advantaged situation (MAS) in terms of income and wealth but more generally on an index of basic goods (rights and opportunities, income and wealth, security, health, education, and culture). In the other state you are at a less advantaged situation (LAS). You therefore face a choice under uncertainty. Clearly your utility (preference or value) is higher under MAS and lower under LAS. You wish to maximize your expected utility (Savage, 1954; von Neumann \& Morgenstern, 1947).

As a rational person you are aware that even though you are choosing a structure of society behind the veil of ignorance, you will live within the rules of the society that you chose. You must affirm the principles of justice you agreed upon regardless of your eventual position in the society (MAS or LAS).

Though you are in the dark about your eventual position in the society, you do have a knowledge of the general laws of human nature. You know that people have different plans for their lives; some wish to be teachers and others entrepreneurs; they practice different religions or spiritual practices; they respond to incentives and weigh effort and leisure uniquely. Thus, the principles of justice chosen in the original position must provide sufficient flexibility for individual aspirations (Mill, 1859).

A paramount objective in the design of a society is that no matter where you eventually end up, you wish to lead a life of dignity with self-respect and wish to be treated as a free and equal person.

I will examine three alternatives for the foundations of a theory of justice. These are: (1) maximize total wealth of the society (free market with minimum government intervention), (2) secure equal liberty and opportunity for all then use the maximin principle for distribution of income and wealth and other basic goods, (3) secure equal liberty and opportunity for all then use expected utility for distribution of income and wealth and other basic goods.

Each of the three alternatives require equal basic liberties (freedom of speech and assembly; liberty of conscience and freedom of thought; freedom from arbitrary arrest and seizure defined by the rule of law; freedom of the person and the right to hold property; political liberty (the right to vote and equal eligibility for public office); and equal access for positions in private and public sectors). Thus, the three alternatives differ chiefly in the distribution of income and wealth. It is worth noting that the principles of justice apply to the basic structure of society and not to the actual specific allocative decisions of society.

Alternative 1, laissez-faire, has its roots in Adam Smith's book The Wealth of Nations, 1776. It has been vigorously defended by Nozick (1974) and Friedman (1980).

Alternative 2 has been proposed by Rawls (1971) and is regarded as the most profound investigation of justice as fairness in modern times.

Alternative 3 may be viewed as a modification of alternative 2 by replacing maximin with expected utility as a principle of distributive justice. 
In Sect. 2, I will provide a brief review of the literature relevant to this paper. In Sect. 3, I define the decision problem from the perspective of a rational individual in the original position. To be consistent, assumption of self-interest is made throughout; though, altruism and other-regarding behavior often influences human choice. Maximization of expected utility of wealth is taken to be the objective function. Arrow (1971) defines utility over wealth in his examination of the measure of risk aversion. This convention is widely used in economics and finance literature. Since Bernoulli, 1738, there has been a tradition to define utility over wealth. Since in the original position, the problem is formulated at a high level of abstraction, income per year could also be used as the outcome.

Subsequent to the formulation of principles of justice, in actual policies either income or wealth or both may be relevant based on the details and intended goals of the policy. The key assumption is that it is possible to assign expectations of wealth (or more generally primary goods) to representative individuals holding various social positions (unskilled labor or managerial class, for example). These expectations are likely to be very far in the laissez-faire system and very close in the maximin system.

Since there is a continuity of systems, I have provided a coherent approach on how these expectations of wealth move in Sect. 4. Two assumptions-utility is concave and redistribution reduces total wealth provide a clarification of alternative principles of distribution. The main results are presented in Sect. 5. Rawls's criticism that probabilities cannot be assigned in the original position is addressed in Sect. 6. An individual seeks more than just income and wealth for her overall wellbeing and happy life. In Sect. 7, I provide a preliminary investigation when utility is impacted by multiple attributes or primary goods. A dedicated scout could generalize the results in this paper considerably by relaxing that even liberty has tradeoffs. Having laid out the implications of the expected utility rule on distribution policies, a detailed comparison with the maximin rule is provided in Sect. 8. In Sect. 9, I respond to criticism of the social minimum policy. Much of these criticisms are for a welfare state where the social minimum is ex-post for victims of ill-luck and the aim is to ensure basic necessities of life for everyone. In my formulation the social minimum is a consequence of a willful ex-ante choice of a rational individual who would ensure for herself provision of education, training, and ownership of productive assets needed for a flourishing life. Finally, in Sect. 10, I provide a summary.

\section{A brief review of literature}

Adam Smith in his magnum opus - "Wealth of Nations" asserted the harmony between the self- interest of individuals and the general interest of society. He coined the phrase "the invisible hand" to demonstrate that a market secures the cooperation of many and distant individuals in the efficient production of goods and services. In the following two well-known passages, he shows that self-interest promotes the welfare of both individual and society. 
"It is not from the benevolence of the butcher, the brewer, or the baker that we expect our dinner, but from their regard to their own interest." Page 16.

"He generally, indeed, neither intends to promote the public interest, nor knows how much he is promoting it.... he intends only his gain, but he is in this, as in many other cases, led by an invisible hand to promote an end which was not part of his intention." Page 421.

In England, the influence of Wealth of Nations was an important factor in bringing about the reforms that remove impediments to free trade. About 200 years later, Friedman popularized free-market solutions in the United States. His effective advocacy brought about the adoption of laissez-faire policies throughout the world.

Adam Smith also wrote, The Theory of Moral Sentiments (1759). In this study of human psychology, he states "How selfish so ever man may be supposed, there are evidently some principles in his nature, which interest him in the fortune of others, and render their happiness necessary to him though he derives nothing from it, except the pleasure of seeing it... The greatest ruffian, the most hardened violator of the laws of society, is not altogether without it."

On balance, Adam Smith regarded that in business and commerce self-interest is the most important propensity. He asks "The industrious knave cultivates the soil; the indolent man leaves it uncultivated. Who ought to reap the harvest?" In economic matters, Adam Smith is clear that benevolence plays a minor role. The main reason is that benevolence grows weaker as the distance between self and others increases.

Nozick (1974), in his thought-provoking thesis formulates, an extreme form of society with a minimal state whose activities are confined to the protection of individuals and their property. He is opposed to redistribution- "Taxation of earnings from labor is on par with forced labor." Page 169. He designs a society from three principles:

1. Justice in acquisition

2. Justice in transfer

3. Rectification of past injustices

The basic idea is that so long as one acquires wealth through his efforts by following the rules of the society and voluntarily participates in any transfer of wealth then one is entitled to keep the fruits of his labor. The third principle permits the rectification of past injustices and permits compensation. To Nozick liberty upends any pre-set pattern of desired income distribution.

Economic freedom based on voluntary exchange espoused by Adam Smith and political freedom espoused by John Stuart Mill (1859) constitute the core of a just society represented in our laissez-faire alternative 1. JS Mill writes, "the sole end for which mankind are warranted, individually or collectively in interfering with the liberty of action of any of their number, is self-protection... in the part which merely concerns himself, his independence is, of right, absolute. Over himself, over his own body and mind, the individual is sovereign."

Our income and wealth in a market economy is determined partly by our choices (education, occupation, effort, etc.) but partly by chance. Our family and cultural 
environment, resources we inherit and the social class we are born into have an influence on our lifetime income and wealth. Further, vagaries of technological change, shifting consumer preference, and ill-luck with health and accidents, disrupt our income and wealth. Alternatives 2 and 3 for the basic structure of just society modify the sole dependence on market outcomes to account for chance events and the contingency of social circumstances.

Rawls (1971, 1999) provided the most profound investigation of justice as fairness in modern times. Rawls key insight is that principles of justice for the basic structure of society are to be agreed on in an initial position of equality when no one knows his place in society. Thus, people "choose together in one joint act, the principles which are to assign basic rights and duties and to determine the division of social benefits" Rawls (1999, page 10). He assumes that parties in the initial situation are rational and mutually disinterested. To Rawls, original position is a purely hypothetical situation-a device to think about principles of justice that are fair. So, the question is which principles of justice would be chosen in the original position?

Rawls concludes that people in original position would choose equality of political rights and would not sacrifice such rights for economic gains. Liberty has absolute weight with respect to social and economic advantages. They would choose equality of opportunity so that offices and positions are open to all without discrimination. Color of your skin or your religion does not determine what positions you can have or not have. Finally, they would choose an economic system that is arranged to benefit the least advantaged. Rawls egalitarian conclusion is:

"All social values - liberty and opportunity, income and wealth, and the bases of self-respect are to be distributed equally unless an unequal distribution of any, or all, of these values is to everyone's advantage." (Rawls, 1999, page 54).

Rawls's work has been scrutinized in a number of fields including political philosophy and economics. His maximin rule for the distribution of income and wealth is perhaps most criticized. Rawls is well aware that the maximin rule would imply that any small benefit to the least advantaged (the worst-off member of society) outweighs any loss to a better-off individual so long as their rank ordering is preserved. His defense of the maximin rule consists of two main parts: first, in the original position risk aversion would be very large so the simplicity of the maximin rule justifies its use; and second that uncertainties in the original position are not expressible by probabilities.

Our alternative 3 is a modification of Rawls's theory that substitutes the expected utility rule for the maximin rule. Since the equality of liberty and opportunity is preserved, the policy implications will differ predominately on the distribution of income and wealth. 


\section{Problem statement}

The three alternatives for a just society that I examine here are in the context of a property- owning democracy with a competitive economic system (Meade, 1964).

In a general problem, an individual wishes to maximize expected utility defined over an index of basic goods (Rawls uses the term primary goods). The three alternatives differ chiefly on their impact on the distribution of wealth between the more advantaged state (MAS) and the less advantaged state (LAS). I will therefore initially focus on the objective: maximization of the expected utility of wealth. The following table represents the decision problem faced by an individual behind the veil of ignorance, where she has a general knowledge of the world, but does not know in which state of the world she will end up.

In Table $1, \mathrm{~W}_{i j}$ represents the wealth position in state $j$ if alternative $i$ is chosen. Now, if the individual can reasonably forecast the state she will inherit then she knows her realized wealth level under each of the three alternative societies. The choice problem is trivial as she can simply choose the maximum in the relevant column. The thought experiment of original position serves as an analytical tool to avoid a self-serving choice. One may assume that the society chosen is for descendants far in future and therefore there is an uncertainty about the outcome.

Assume the individual subscribes to the axioms of von Neumann and Morgenstern (1947) and Savage (1954) and therefore guides her choice by maximization of expected value of her utility defined over wealth. For now, let us assume that all individuals in the society have the same utility function. Thus, a utility function, $U$, is a representative utility for the society as a whole.

$$
\text { Expected Utility for Alternative } i=\sum_{j=1}^{2} P_{j} U\left(W_{i j}\right)
$$

In (1), $P_{j}$ is the probability that state $\mathrm{j}$ will occur, $\sum P_{j}=1$. Utility function $U$ measures the weight of the outcome in decision-making. It is worth emphasizing that utility in our formulation is not Benthamite utility (Bentham, 1789) that measures satisfaction of desire or happiness. In Bentham's utilitarian “greatest happiness" principle, the total utility is maximized; for a fixed population size total utility or average utility will yield identical prescriptions. If we assume that the individual has equal likelihood of realizing the outcome of any one member of the society then she too will use the average utility in (1) to choose among alternatives.

Table 1 Decision problem

\begin{tabular}{lll}
\hline State $j$ & More advantaged state (MAS) & Less advantaged state (LAS) \\
\hline Alternative $i$ & & \\
Alternative 1 (Laissez-faire) & $W_{11}$ & $W_{12}$ \\
Alternative 2 (Maximin) & $W_{21}$ & $W_{22}$ \\
Alternative 3 (Social minimum) & $W_{31}$ & $W_{32}$ \\
\hline
\end{tabular}


Though the functional form in (1) is the same as in the utilitarian rule, the utility construct in decision theory is derived from choices between prospects involving risks.

Utility, in our framework, reflects attitudes towards risk and though cardinal (unique up to a positive linear transformation), is not intended to provide a basis for interpersonal comparisons. Some, notably Harsanyi (1975), have vociferously argued that utility reflects strength of preference. Additional assumptions are, however, needed to justify the strength of preference interpretation (see Sarin, 1982).

\section{Two assumptions}

We have defined the choice of a society from a single rational individual's perspective. Which society would you rather live in if you do not know your position in the society? Without further assumptions, the choice of a society is merely a personal preference akin to a choice of a color from blue, red, and yellow.

How should a single individual decide which society is best suited for realizing her goals and objectives in life? Our formulation of the decision problem in (1) assumes maximization of expected utility over wealth. A more general formulation where utility is defined over multiple objectives is discussed later.

\subsection{Assumption 1: a representative individual's utility function is concave}

Concavity has been a well-accepted property of utility function since Bernoulli (1738). Bernoulli used an interpretation of diminishing marginal value (1 ducat to poor is worth more than 1 ducat to rich). Bernoulli states "the utility resulting from any small increase in wealth will be inversely proportionate to the quantity of goods previously possessed." The only mathematical form satisfying $U^{\prime}(W)=\frac{1}{W}$ is, of course, log utility. Bernoulli gives the following example from his cousin to justify concavity of utility, "Peter tosses a coin and continues to do until it should land 'heads' when it comes to the ground. He agrees to give Paul one ducat if he gets 'heads' on the very first throw, two ducats if he gets it on the second, four if on the third, eight if on the fourth, and so on, so that with each additional throw the number of ducats he must pay is doubled. Suppose we seek to determine the value of Paul's expectation." P. 31. Since the probability of heads on the $n$th throw is $2^{-n}$ and Paul receives $2^{n-1}$ ducats, Paul's total expectation is $\frac{1}{2}+\frac{1}{2}+\ldots \frac{1}{2}+\ldots$, and that is infinite. With $\log$ utiity, Bernoulli shows that such a gamble is worth only a few ducats. In modern utility theory, risk aversion is a preference for the expected value of a lottery to taking a chance on the outcomes of the lottery. Thus, a risk averse individual will prefer a sure wealth of 50 over a lottery that yields a wealth of 100 with a 0.5 chance and a wealth of 0 with a 0.5 chance.

In modern utility theory, maximization of expected utility is derived from some reasonable axioms and not simply assumed. Further, utility measures the weight of outcomes in decisions and is derived from preferences and not through introspection. In the original position, an individual who wishes to enter one of the three 
societies, may accept risk aversion as a general trait. Nevertheless, she would not want her choice about the structure of society to depend on the precise degree of risk aversion. The original position permits a general knowledge of the world but not of individual circumstance and attitudes.

Each of the three alternative societies under consideration has a redistribution policy. An individual is free to choose a redistribution policy that shifts wealth from one state (MAS) to the other state (LAS).

A redistribution, however, lowers output because of incentive effects and inefficiencies of transfer. Prior to redistribution, wealth in the state MAS is high, $H$, and in the state LAS is low, $L$.

An obvious point that is worth noting is that there need not be a literal transfer of wealth in a sack from MAS to LAS. An alternative that ensures a basic level of healthcare, education and old age pension; for example, will have less difference in wealth between MAS and LAS as compared to laissez- faire. Our simplification in modeling omits these details but at a cost. Incentive effects and inefficiencies of transfer may well depend on how such a transfer is carried out.

\subsection{Assumption 2: there is a shrinkage in transfer from the high wealth state (MAS) to the low wealth state (LAS)}

Incentive effects of redistribution have been recognized in economics since Edgeworth (1881) and possibly before that. Marshall (1907) observed that a more equal distribution of wealth would likely diminish aggregate wealth. A more modern account of inefficiencies of redistribution is Okun's (1975) leaky bucket experiment.

Suppose you transfer $\$ 100$ from MAS but only $\$ 80$ is received in LAS. Where did the $\$ 20$ go? Okun's answer is that the transfer is carried out in a leaky bucket and $20 \%$ of the content leaked out. Of course, the leaky bucket is a metaphor for the administrative costs, reduced or misplaced work effort, distorted saving and investment behavior, and possible changes in socioeconomic attitudes. A reasonable leak may be acceptable if the transfer creates a greater equality of opportunity for those at the bottom so successive generations are not trapped in the lower socioeconomic class. There are abundant examples of individuals and communities who achieved self-sufficiency and even prosperity when access to education, capital, and jobs was improved. I will assume the existence of the leak but discuss in a subsequent section the arc of improvement when the leak is reduced.

To increase the wealth by $x$ in LAS, one needs to transfer $\alpha x, \alpha \geq 1$, from MAS.

Thus, an increase of \$1 in LAS, requires a decrease of \$2 in MAS if $\alpha=2$. Thus $50 \%$ of the transfer leaks out because of the incentive effects and administrative costs. We can interpret $\alpha$ as output reduction in the more advantaged state per unit of amount transferred to the less advantaged state.

A simple example illuminates the principle of transfer in assumption 2. Suppose the individual in the original position anticipates a wealth level 100 in MAS and 0 in LAS; each state is equally likely. She fears the prospect of landing up with zero and is therefore willing to commit a transfer from MAS to LAS. Assuming $\alpha=2$, to ensure a wealth level of 20 in LAS, she must transfer 40 from MAS. At the 
completion of the transfer she will have a wealth level of 60 in MAS and 20 in LAS. She prefers the less uneven outcomes after redistribution to initial outcomes of either 100 or 0 . In our hypothetical original position, such a planned redistribution may improve expected utility. It is an ultimate life insurance of a sort. I believe Nozick will deem this voluntary redistribution plan to be consistent with his principle of "justice in transfer" applied in the original position. Of course, Rawls will approve with gusto and would wish to go quite far in redistribution.

\section{Main result}

We now derive the optimal redistribution from the more advantaged state to the less advantaged state for an individual who wishes to maximize her expected utility in the original position. We will assume the utility function to be concave and that redistribution reduces total wealth. In the "Appendix", more details are provided.

Prior to redistribution, the individual expects to be either in a high wealth position, $H$, or in a low wealth position, $L$, with equal chances. Assume that $\alpha$ is the reduction in wealth in the more advantaged state per unit of wealth received in the less advantaged state. We will assume $\alpha$ to be constant and thus independent of the amount of wealth transferred.

Expected utility of individual before the transfer is:

$$
\frac{1}{2} U(H)+\frac{1}{2} U(L)
$$

Expected utility of the individual after the transfer is:

$$
\frac{1}{2} U(H-\alpha x)+\frac{1}{2} U(L+x) .
$$

where $x$ is the amount received in the less advantaged state. Clearly, $H-\alpha x \geq$ $L+x$, or $x \leq \frac{H-L}{1+\alpha}$ so as not to reverse the order of the wealth position in two states. An optimal amount of redistribution $x^{*}$ is obtained by

$$
\begin{array}{r}
{ }_{x}^{\operatorname{Max}} U(H-\alpha x)+U(L+x) \\
\text { s.t. } x \leq \frac{H-L}{1+\alpha}
\end{array}
$$

Intuitively, in the optimal redistribution, the utility of a one-unit gain in the less advantaged state just matches the utility of $\alpha$ units loss in the more advantaged state. The optimal $x^{*}$ is obtained by solving:

$$
\frac{U^{\prime}\left(L+x^{*}\right)}{U^{\prime}\left(H-\alpha x^{*}\right)}=\alpha
$$

To obtain some insights from (2), we need to know the degree of risk aversion $\left(-U^{\prime \prime} / U^{\prime}\right)$ and the magnitude of $\alpha$. Okun proposed (his personal preference) an acceptable leakage of no more than $60 \%$; i.e., $\alpha \leq 2.5$ (Leak $=1-\frac{1}{\alpha}$ ). 
For an illustrative example, assume a Bernoullian utility $(\log W)$. Using (2) the optimal $x^{*}$ is given by,

$$
x^{*}=\frac{H-\alpha \mathrm{L}}{2 \alpha}
$$

Suppose $H=100, L=10$, and $\alpha=2$. Before redistribution the individual has an equal chance of being in the more advantaged state (MAS) with a wealth level of 100 and in the less advantaged state (LAS) with a wealth level of 10 . To maximize her expected utility, she will be willing to give up $\alpha x^{*}$ of her wealth in the more advantaged state so that after the incentive effects and inefficiencies of transfer, she receives an $x^{*}$ increment to her wealth in the less advantaged state.

Using (3), $x^{*}=20$, and thus after the redistribution she will have a wealth of 60 in the more advantaged state and a wealth of 30 in the less advantaged state. Why not push the redistribution even further till one achieves an equal wealth level in both states? At least in this example, and perhaps in many other examples with a reasonable level of concavity of utility function and a reasonable assumption on leak, an extreme transfer that forces an equal wealth level in both states does not maximize expected utility. If so, other considerations must be invoked to require a wealth transfer to the point of equality.

In Table 2, we summarize the outcomes obtained for the three alternative societies for our illustrative example.

It is easy to see that with $\log$ utility and $\alpha=2$, laissez-faire has the lowest expected utility $[\log (100 * 10)]$ and social minimum has the highest expected utility $\log [60 * 30]$ with maximin somewhere in the middle [log $(40 * 40)]$.

The message of this illustrative example, is that redistribution up to a point is desirable but excessive redistribution reduces total wealth and thereby lowers the expected utility. The social minimum of 30 units in the less advantaged state is the optimal redistribution.

An important extension of the above result for the optimal redistribution is to consider the case when the proportion of people in MAS is lower than the proportion of people in LAS. To fix ideas, suppose there is one person in MAS and two persons in LAS. Thus, in the original position where you do not know which person you would turn out to be, the probability of being in MAS is $\frac{1}{3}$ and that for being in LAS is $\frac{2}{3}$. If in a transfer, each person in LAS receives $\$ 1$, then $\$ 2 \alpha$ must be transferred from MAS.

Table 2 Wealth distribution under three societies

\begin{tabular}{llll}
\hline State & More advantaged state & Less advantaged state & Utility (Rank) \\
\hline Alternative & & & \\
Laissez-faire & 100 & 10 & Worst (3) \\
Maximin & 40 & 40 & Intermediate (2) \\
Social Minimum & 60 & 30 & Best (1) \\
\hline
\end{tabular}


Suppose the proportion of the population in MAS is $p_{1}$ and in LAS is $\left(1-p_{1}\right)$. Let $t=\left(1-p_{1}\right) / p_{1}$

Expected utility of the individual before the transfer is:

$$
p_{1} U(H)+\left(1-p_{1}\right) U(L)
$$

Expected utility of the individual after the transfer is:

$$
p_{1} U(H-\alpha t x)+\left(1-p_{1}\right) U(L+x),
$$

where $x$ is the amount received in the less advantaged state. So as not to reverse the order of the wealth position in two states, $H-\alpha t x \geq L+x$.

An optimal redistribution is obtained by maximizing $p_{1} U(H-\alpha t x)+\left(1-p_{1}\right)$ $U(L+x)$ subject to the rank order constraint. In the optimal redistribution, the utility of a 1-unit gain in the less advantaged state just matches the utility of an $\alpha t$ units loss in the more advantaged state. The optimal $x^{*}$ is obtained by solving:

$$
\frac{U^{\prime}\left(L+x^{*}\right)}{U^{\prime}\left(H-\alpha t x^{*}\right)}=\alpha
$$

For log utility the optimal redistribution is given by,

$$
x^{*}=\frac{H-\alpha L}{\alpha(t+1)}
$$

The recognition that the proportion of people differ in two states has important implications in an actual distribution policy that may arise after the principles of justice have been accepted. For example, consider a special tax on the top $10 \%$ to provide educational and training opportunity to the bottom $20 \%$ who might have fallen behind because of technological change. This extension preserves the concept of social minimum as a policy and may generally differ from the policy of maximizing the well-being of the least advantaged.

In Sect. 7, I will provide a broader justification of the social minimum as an alternative to the maximin principle for the redistribution policy of a just society.

The idea of the principle of the social minimum in the original position is not to identify the exact level of the minimal amount once and for all. To do so will require an exact specification of the utility function. A redistribution policy is determined by elected representatives and will take into account a host of factors including a society's level of wealth and prevalent social conditions. Once the veil is lifted, more detailed information on citizens' preferences and their economic and social conditions is available. The principle of the social minimum that has been agreed upon in the original position must be honored and in spite of differences in inclinations, a genuine attempt must be made to secure a decent life for all citizens. The social minimum is to be conceived as providing each citizen the opportunity to realize one's life plan and thus live a life of dignity with self-respect. Social minimum serves the purpose of a trampoline so people can engage in entrepreneurial activities and enhance their life plans. I note that the social minimum is not exogenously imposed as in Waldron (1986) or Rawls (2001) to 
meet the minimal essential needs of life. Instead, the social minimum is derived from expected utility maximization and is likely to be well above the immiseration level.

\section{Behind the Veil}

Imagine a situation in which a single rational individual is to choose one of the several societies to join. In the original position, our hypothetical joiner reasons probabilistically that she has an equal chance of being either in the more advantaged state or in the less advantaged state.

Table 2 shows the payoffs (in thousands of dollars). The payoffs depend on the alternative chosen and the state that eventually occurs. If the individual maximizes expected monetary value in her decision to choose a society, she will choose laissezfaire. If, instead, she maximizes the worst outcome, as Rawls advocates, she will choose maximin. For a large set of utility functions, an expected utility maximizer will choose an optimal redistribution that lies somewhere between no redistribution and equal wealth in both states. Exclusive focus on the worst outcome to choose a society to enter assumes an extreme risk aversion.

Let us consider two arguments that Rawls uses to justify the use of the maximin rule.

The first argument is that in the original position risk aversion will be so large so the simplicity of the maximin rule justifies its use. Arrow (1973), Harsanyi (1975), Musgrave (1974) and many others do not agree with the assertion of extreme risk aversion. Nevertheless, whether an individual would be so cautious as to guide her choice of the basic structure of society solely by the worst outcome needs to be debated.

Rawls's second argument is that when one is choosing in the dark about the entire life's prospects, probabilities are ill-defined. There has been a recurrent controversy whether the expected utility theory has a normative appeal in decisions under ambiguity (unknown probabilities). Savage (1954) provides an axiomatic justification for representing all uncertainties by subjective probabilities and using these probabilities in expected utility calculations. But the contrary view has been expressed by Keynes (1921), Knight (1921) and Ellsberg (1964).

A simple example illustrates the reluctance of Rawls for using probabilistic reasoning when there is no actuarial or logical basis for assigning probabilities. The example given by Ellsberg illustrates that people prefer to bet on the outcome of an urn that contains 50 yellow and 50 white balls rather than the outcome of an urn that contains 100 yellow and white balls, but in an unknown proportion. In the former bet, the probability of drawing a yellow or white ball is precisely 0.5 , while in the latter bet this probability is ambiguous or vague. Presumably, people like the specificity of probability to vagueness in probability.

Suppose, we accept that behind the veil, one may not weight equally the more advantaged state and the less advantaged state as the probabilistic reasoning or the principle of insufficient reason requires. It does not, however, follow that the entire weight must be assigned to the less advantaged state and none to the more 
advantaged state. Schmeidler (1989) (also see Sarin \& Wakker, 1992) showed that a consistent scheme of preferences can be obtained without requiring additivity of probability. In fairness, Rawls was not aware of these recent developments and a large volume of literature that has built on Schmeidler's novel modification of Savage's subjective expected utility.

If $\mathrm{H}$ is the wealth in the more advantaged state and $\mathrm{L}$ is the wealth in the less advantaged state, the overall evaluation in the original position would be as follows:

$$
\underset{\text { (SEU) }}{\text { Savage }}: \frac{1}{2} U(H)+\frac{1}{2} U(L)
$$

Schmeidler : $\pi_{1} U(H)+\left(1-\pi_{1}\right) U(L), \quad \pi_{1}<0.5$

(CEU)

Thus, in Schmeidler's Choquet Expected Utility (CEU) a higher weight is assigned to the less advantaged state and a lower weight is assigned to the more advantaged state. Notice that in both subjective expected utility theory or Choquet expected utility theory, utilities already reflect risk aversion. Rawls seems to impose that, in spite of a cautious weighting of outcomes (risk aversion), the less advantaged state must receive the entire weight in the choice.

We now explore redistribution policies under the CEU model.

Under SEU Eqs. (2) and (3) are used to determine the optimal transfer from the more advantaged state to the less advantaged state. Under CEU, the optimal transfer will be larger under the reasonable assumption that the individual dislikes ambiguity.

The CEU of the individual before the transfer is:

$$
\pi_{1} U(H)+\left(1-\pi_{1}\right) U(L) .
$$

The CEU of the individual after the transfer is:

$$
\pi_{1} U(H-\alpha x)+\left(1-\pi_{1}\right) U(L+x) .
$$

The amount of transfer $x$ is limited so as not to reverse the order of the wealth position in the two states. An optimal redistribution is obtained by,

$$
{ }_{x}^{\operatorname{Max}} \pi_{1} U(H-\alpha x)+\left(1-\pi_{1}\right) U(L+x),
$$

where $0 \leq \pi_{1} \leq \frac{1}{2}$. The optimal $x^{*}$ is obtained by solving:

$$
\frac{U^{\prime}\left(L+\mathrm{x}^{*}\right)}{U^{\prime}\left(H-\alpha x^{*}\right)}=\alpha\left(\pi_{1} /\left(1-\pi_{1}\right)\right)=\alpha \theta
$$

In (4), $\theta=\pi_{1} /\left(1-\pi_{1}\right)$ reflects the ratio of the weight of the more advantaged state to the weight of the less advantaged state. For SEU, both states are equally weighted and thus $\theta=1$.

For a Bernoullian utility $(\log \mathrm{W})$ under CEU, the optimal transfer to the less advantaged state is given by, 


$$
x^{*}=\frac{H-\alpha L \theta}{\alpha(\theta+1)} .
$$

Again, note that for $\theta=1$, there is no ambiguity aversion, as both states are weighted equally, and the optimal transfer is what the SEU maximizer would choose. Further, recall that $x^{*} \leq \frac{H-L}{1+\alpha}$ so that the transfer is carried out only up to the point where the outcome in MAS does not become lower than the outcome in LAS.

In our illustrative example, $H=100, L=10, \alpha=2$. Using (5), we can compute the optimal transfer from MAS to LAS for a few representative values of $\theta$. The maximum allowable transfer in this example is constrained to be 30 units, since that results in equal wealth for all.

\begin{tabular}{llll}
\hline$\theta$ & Optimal transfer & Wealth in MAS & Wealth in LAS \\
\hline 1 & 20 & 60 & 30 \\
0.75 & 24.3 & 51.4 & 34.3 \\
0.50 & 30 & 40 & 40 \\
\hline
\end{tabular}

The key purpose of this example is to show that even when we assume aversion to ambiguity, the maximin solution obtains when the capacity or the decision weight $\pi_{1}$ of the more advantaged state is less than or equal to $\frac{1}{3}$ and of the less advantaged state is more than or equal to $\frac{2}{3}(\theta \leq 0.5)$.

Figure 1 below shows the region of optimal redistribution with laissez-faire (A) and maximin $(\mathrm{R})$ as two extreme points on the line segment AR depicting all possible redistributions.

In Fig. 1, point $\mathrm{A}$ is the pre-distribution point. For an expected utility maximizer, the optimal redistribution is point $S$ that is obtained by transferring wealth $\alpha x$ from the more advantaged state but because of a leak the wealth in the less advantaged state increases only by $\mathrm{x}$.

Fig. 1 Optimal redistribution Optimal Redistribution Behind the Veil behind the Veil

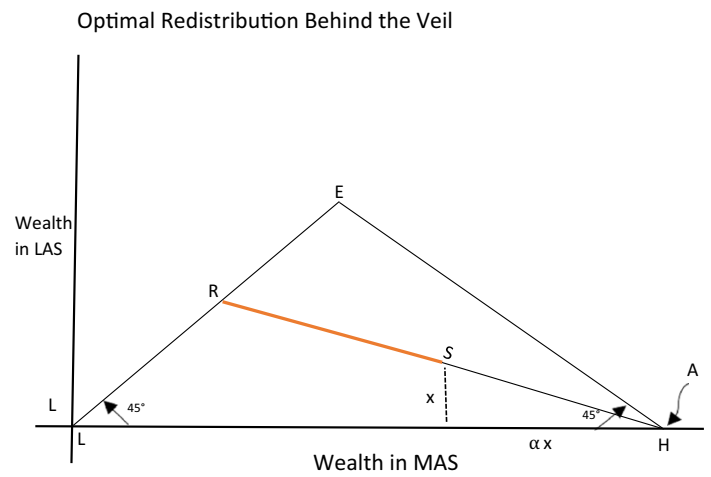


For a Choquet expected utility maximizer, with ambiguity aversion, some point on the segment SR will be optimal. The extreme egalitarian transfer to point $\mathrm{R}$ requires a high degree of ambiguity aversion.

Arrow (1973), Harsanyi (1975) and several other authors have noted that the maximin rule proposed by Rawls assumes a high degree of risk aversion if redistribution policies are evaluated using the expected utility criterion. For the class of constant relative risk aversion (CRRA) utilities, the maximin rule is approached as the coefficient of relative risk aversion approaches infinity. It is reasonable to have a high degree of risk aversion in the original position, since stakes are high, but the sole focus on the worst possible outcome the maximin requires is an extreme form of risk aversion. Rawls's response to this criticism is that because of ignorance in the original position, probabilities are ill defined and thus the assumption of equal chance of being in each state is invalid. The relatively new development of Choquet expected utility permits assigning a higher weight to the less advantaged state. The optimal redistribution shifts more towards equality. Maximin, nevertheless, is an extreme point. For low degrees of risk aversion and ambiguity aversion, the optimal redistribution will be small and the final wealth positions will be closer to starting point A (laissez-faire). For high degrees of risk and ambiguity aversion, the optimal redistribution will be significant and the final wealth positions will be closer to point $\mathrm{S}$ (maximin). Similarly, if the leak is low, the optimal redistribution will be high and the final wealth positions will be closer to point E. Rawls nowhere argues that there is no productivity loss and the redistribution moves along the line $\mathrm{AE}$ or closer to the $-45^{\circ}$ line. In Rawls (1999) and Samuelson and Nordhaus (2010), the redistribution curve moves sharply away from the line AE implying productivity loss. It is worth noting, though obvious, that with $\alpha=1$ (no leak), the optimal redistribution will be an equal division (point E) even with the smallest risk aversion.

Redistribution policies characterized by the social minimum that lie between laissez-faire (no redistribution) and maximin (equal division) seem more acceptable under a wide range of attitudes towards risk and ambiguity and reasonable assumptions on leakage due to incentive effects, effort-leisure tradeoffs and administrative inefficiencies.

\section{Social minimum}

In a democracy with a competitive economic system (context of our investigation), business of society is best performed by private and voluntary organizations. We have shown that a rational individual, in the original position, would choose a society that has a redistribution policy that strikes a balance between efficiency (total output) and equality. In the example in Table 2, suppose the more advantaged state is above median wealth and the less advantaged state is below median wealth. In a society with social minimum the individual would ensure a $\$ 30,000$ wealth in the less advantaged state but will only receive $\$ 60,000$ in the more advantaged state. In contrast in a laissez-faire society, she receives a much smaller amount of $\$ 10,000$ in the less advantaged state but receives a greater amount of $\$ 100,000$ in the more 
advantaged state. Within the assumptions of the example, the social minimum society is preferred to both the laissez-faire and the maximin societies.

The choice of a society does not depend only on the economic system that predominately determines the distribution of income and wealth under alternative states. An individual desires to live a life of dignity with self-respect and be treated as a free and equal person (Rawls, 1971). Distribution of liberty, for example, is equally important. Thus, utility function is defined over multiple attributes, the maximization of which then approximates a happy life. A society where some citizens are not allowed to vote, based on income, gender, or race (poor in England until the Representation of the People Act 1918, women in the US until 1920 and in Saudi Arabia until 2015), for example, will not be deemed desirable in the original position. I will assume that in the original position a rational individual will affirm Rawls's "First Principle" that a society must assure each citizen equal basic rights and liberties. These include freedom of thought and liberty of conscience; political liberties (the right to vote) and freedom of association (religious freedom); and rights and liberties covered by the rule of law. These rights and liberties are to be guaranteed. I do note that in some phases of society the liberty may be somewhat restricted to preserve social order. In Singapore, for example, one is free to practice one's religion of choice but may not publicly criticize other religions. With so many religions practiced in a small close-knit society, such restriction promotes social order and harmony.

In addition to liberty, a society must ensure a fair degree of the equality of opportunity.

Regardless of race or religion, for example, an individual should be able to hold an office, pursue higher education, and choose a career in public or private sector. Finally, in a democratic society with a competitive free market economic system, individuality (freedom to pursue one's life plan and fair chance to attain it) must be encouraged.

In a social minimum society, an individual maximizes utility defined over a comprehensive set of attributes that include income and wealth, liberty, opportunity, and individuality. The conception of such a society can be stated as follows:

The basic structure of society (the main political, social, and economic institutions) is to be designed so that each individual is free to maximize expected utility over one's lifetime within the restriction that all individuals are guaranteed a suitable minimum for a life of dignity with self-respect.

For such a social minimum society, we need to answer two questions. First, what is the logic for maximizing expected utility subject to a constraint of maintaining a suitable social minimum? Second, how do we determine the social minimum that is between laissez-faire and maximin in Fig. 1?

To answer the first question, we follow the idea of Rawls about primary goods. Behind the veil of ignorance, where one has only general information about one's preferences and a broad knowledge about the conditions of human life, primary goods such as liberty and opportunity, and income and wealth are desired by all. I agree with Arrow (1973, Page 254) and add health to the list of primary goods. One may also wish to add education and training necessary for succeeding in a market economy, and security that influences well-being throughout a life. Primary goods 
are what an individual needs as a free and equal person to live a life of dignity with self-respect. For my purpose, primary goods specified by Rawls suffice. A thorough analysis would entail constructing a value tree of hierarchy of objectives starting with "the life of dignity with self-respect". Keeney and Raiffa (1976) provide a systematic approach to the construction of a value tree.

A rational individual contemplating the design of a society where she would rather live needs to evaluate alternative designs on multiple dimensions-each dimension being a primary good. It is quite possible that there is a correlation among primary goods in a state. In a more advantaged state, for example, one is endowed with a higher wealth level but may also enjoy a higher position of authority. The reverse may be true, lower wealth and lower authority, in the less advantaged state. Rawls (1999, pages 79-81) defines an index of primary goods and thus reduces a multi-attribute utility problem into a single attribute utility defined over the index of primary goods.

Rawls discusses the construction of the index of primary goods. He argues that the index- number problem in commensurating the different goods is not so difficult for two reasons. First, because the basic liberties are equal and there is equality of opportunity, only the primary goods of wealth and income and the rights and prerogatives of authority vary in their distribution. In our framework, the set of attributes is considerably reduced. Second, because of the maximin rule (the difference principle for Rawls), one only needs to identify the index for the least advantaged group. Nevertheless, even to identify the least advantaged group, an interpersonal comparison is required to establish the rank order. It is not uncommon to observe that groups deprived of adequate healthcare, political rights, or low in income and wealth each may feel that they are the least advantaged. Rawls recognizes that tradeoffs between primary goods cannot be avoided.

Hart (1973) argues persuasively that some liberties such as freedom of religion cannot be traded with economic advantage but others could be. He states "If, for example, it could be shown that unrestricted freedom of movement over land would tend to reduce everyone's food supply, whereas no bad consequences likely to affect everyone would result from the other alternative, then the conflict should be resolved in favor of restriction of movement". Hart is questioning the lexicographic ordering of liberty over income and wealth (Rawls, page 266). Hart favors "weighting of advantage and disadvantage must always be required to determine whether the general distribution of any specific liberty is in a man's interest". Rawls is emphatic "they will not exchange a lesser liberty for greater economic advantages" (page 475).

Our focus is on redistribution policies under alternative systems of justice and thus we have restricted our attention to wealth or a simple index of primary goods defined preferably in terms of equivalent wealth.

Consider an example where wealth and health are two primary goods. An individual will have a higher wealth and a higher measure of health (measured for example in quality-adjusted life years, QALY) in the more advantaged state and a lower wealth and a lower health measure in the less advantaged state.

Figure 2 shows the indifference curves reflecting tradeoffs between wealth and health. 


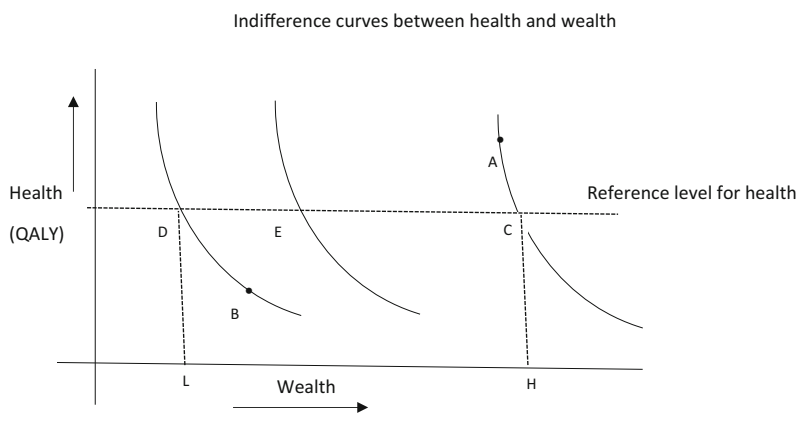

Fig. 2 Indifference curves between health and wealth

An individual in the original position faces a 50-50 lottery between A and B. Since $A \sim C$ and $B \sim D$; the original lottery is equivalent to the 50-50 lottery between $\mathrm{C}$ and $\mathrm{D}$. We have thus reduced the choice problem to one dimension (call it equivalent wealth or index of primary goods) keeping the other dimensions constant at a suitably chosen reference level. There is an implicit assumption (utility independence) that the choice of the reference level does not impact the rank ordering of lotteries on equivalent wealth.

If there are $n$ dimensions or primary goods in addition to wealth then we can use the same procedure by fixing reference levels for these $\mathrm{n}$ dimensions and then obtaining an equivalent wealth $\hat{w}$ so that

$$
\left(w, x_{1}, x_{2}, \ldots, x_{n}\right) \sim\left(\hat{w}, \bar{x}_{1}, \bar{x}_{2}, \ldots, \bar{x}_{n}\right),
$$

where the LHS is the original bundle of primary goods and RHS is the bundle where the wealth dimension is adjusted by successively moving the other dimensions to their respective reference levels. We will call the equivalent wealth so obtained as the index of primary goods.

Consider in Fig. 1, the axes represent the index of primary goods rather than the wealth. So the rational individual faces a decision problem under uncertainty where she obtains a higher index in the more advantaged state but a lower index in the less advantaged state. A higher index of primary goods is preferred as regardless of one's goals in life (not known behind the veil), a higher index enables a greater success in achieving these goals.

A rational individual would commit to a redistribution policy, assuming she has some degree of aversion to uncertainty, and will balance the outcome (the index of primary goods) in the more advantaged state with that in the less advantaged state. This balancing is achieved through the maximization of expected utility. The point $\mathrm{S}$ in the modified Fig. 1 (axes represent the index of primary goods rather than wealth), is the optimal redistribution that we call social minimum.

Rawls has a strong commitment to egalitarianism and regards the distribution of natural talents or superiorities of intelligence or strength are common asset to be distributed equally. He would choose the point R in Fig. 1 with an equal index of primary goods in both states. I leave the detailed comparison of the Social Minimum with the Rawlsian society to the next section. The key distinction is that Rawls 
emphasizes the least advantaged; whereas, the social minimum strikes a balance between the upside and the downside as dictated by the rational theory of choice under uncertainty.

I now take up the second question: where on the segment AR is the social minimum point $\mathrm{S}$ ?

With some general assumptions about preferences - a higher index of primary goods is desired and there is some degree of aversion to uncertainty - a rational individual (expected utility maximizer) would prefer a redistribution policy on the line segment AR with the end points being laissez-faire (no redistribution) and maximin (equal distribution). As the degree of risk aversion increases, one moves from point A to $\mathrm{R}$. The social minimum is simply an interior point on AR.

The social minimum point $\mathrm{S}$ is determinate for a specified utility function. For a CRRA family, one can assume the coefficient of relative risk aversion to be in a range say between $1 / 2$ (Cramer utility) and 1 (Bernoullian utility) and then we can derive the range within which the social minimum would fall (see the "Appendix"). One may also use a utility function for a representative individual. Arrow (1971) provides a theoretical argument for the relative risk aversion to be near 1. Stigler and Becker (1977) have argued that deep utility is identical across individuals. With Bernoullian log utility the social minimum is given in Table 2. The numbers in Table 2, however, represent levels of the index of primary goods rather than the wealth alone.

Waldron (1986) makes a case that the social minimum should be set at just above the level of immiseration. The logic is to avoid discontent. Rawls (1999, page 252) argues for his maximin approach "the minimum is to be set at that point which, taking wages into account, maximizes the expectations of the least advantaged group". Both of these approaches only look at the downside, i.e., consequences in the less advantaged state. Our approach strikes a balance between the upside and the downside.

A rational individual will choose a social minimum based on the maximization of expected utility. The social minimum needs to be periodically adjusted to changing social and economic circumstances. In our example in Fig. 1, with log utility, if the wealth of the society uniformly doubles, then the optimal redistribution also doubles.

A commitment to the social minimum should be a part of the ethos of society. The social minimum affirms the equality of political rights (free speech, right to vote, trial by jury, religious freedom, etc.), a fair equality of opportunity (no discrimination based on race, religion, or gender; equal access to education, training, and jobs; careers open to talents in both private and public sector) and a balance in the distribution of income and wealth. 


\section{Comparison with maximin}

Rawls's (1971, revised edition 1999) monumental work provides a justification for the two principles of justice for institutions (see pages 266-267 in the revised edition). These principles can be described in three steps in a lexicographic order. Step 1 takes priority over step 2 and step 2 takes priority over step 3 .

Step 1 Equality of political rights

Each person has an equal right to vote, freedom of speech and association, liberty of conscience and other basic liberties.

Step 2 Equality of opportunity

Offices and positions are open to all and there is no discrimination based on the race, religion, or gender.

Step 3 Maximin rule

The economic system is to be arranged to benefit the least advantaged.

Because of lexicographic ordering, no amount of economic well-being can compensate for a loss of liberty. Though some have reservations about the lexicographic order, most notably Hart (1973), I will assume that all three systems (laissez-faire, social minimum and maximin) examined in this paper satisfy steps 1 and 2 and thus differ chiefly on their economic systems and associated redistribution policies.

The question is: what are the implications of an economic system on the political social order?

Laissez-faire relies on free markets to determine the distribution of wealth and income. Proponents of laissez-faire such as Adam Smith, Hayek, Friedman, and Nozick argue for a minimum intervention in the workings of a market and oppose heavy handed redistribution of income and wealth. The argument is that under laissez-faire total output is maximized. Further, any redistribution of income interferes with liberty. Nozick compares a redistribution to forced labor. In a colorful example, he challenges us to suppose that people voluntarily pay 25 cents to watch Wilt Chamberlain play basketball. The result is that at the end of the year Wilt receives $\$ 250,000$. Is he entitled to this income?

Suppose in the original position, when Wilt was a child, his father William is given a choice: accept the market earnings for his son regardless of how Wilt turns out to be (a basketball player or a long jumper) or accept a balanced earnings profile achieved through redistribution. With any modest degree of risk aversion, a balanced earnings profile will likely have a higher expected utility than that of a boom (basketball player)—bust (long jumper) earnings profile. Even though original position is not to be used as an analytical tool for an individual situation, it does illustrate that a redistribution policy that seems unfair ex-post may be deemed quite acceptable ex-ante. Incidentally, Wilt in his younger years was a very good long jumper and was disinterested in basketball.

I now examine the consequences of the social minimum and the maximin systems of redistribution on political and social order.

In the maximin system, there is a strong emphasis on egalitarianism and income and wealth are to be distributed equally unless unequal distribution is to everyone's 
disadvantage. But what rationale should the institutions of a society use to equalize the income of a star baseball player with that of a juggler on the main street (both bring happiness and receive applause) or of an entrepreneur and a school teacher.

The noble value judgment Rawls makes is that the distribution of natural talents, intelligence, or strength are a common asset and therefore do not by themselves deserve greater rewards. The maximin rule then allows the sharing of the greater rewards won through these talents.

Even though one may accept that an endowment of natural talents is undeserved, some people choose to cultivate these talents through effort and perseverance. Further, people choose their career or life's plans based on their goals and objectives. Market forces do not reward a manager and a priest the same way though both may show high commitment and excellence in their respective pursuits.

Market rewards are driven by supply and demand and do not always accord with our intuitive judgments of deservedness and value.

An unequal income distribution may come about because of the effort-leisure tradeoff. If a group of religious people choose to pray and engage in the activities of the church for 4 hours a day and work for only 4 hours, how far should the redistribution go to compensate them for the earnings foregone? Is there a difference between the lower earnings of a surfer who spends better part of the day surfing and a worker whose work hours are reduced because of technology?

Rawls is correct that the least advantaged group is easy to identify, specially on income. But are all such groups deserving of redress through redistribution? Friction in society is usually created when people find the redistribution undeserving.

The social minimum may have the same issues if not properly designed. Opportunities for education and training, provision of essential healthcare, financing to start a family business, security of person and property, income support for elderly through social security or savings programs, income support for low income groups, nutrition and education for children from an early age and other such targeted programs as a part of the social minimum are likely to be widely endorsed. A direct income transfer such as a basic income to all or a variant is perhaps most contentious because in a competitive economy people develop deep rooted beliefs that money rewards are deserved by those who contribute to the product of the society. Perhaps a system of workfare as developed in Singapore is more acceptable. We are far from accepting that talents and hard work are a common pool, the rewards of which are to be equally distributed.

If we want trapeze artists to innovate and perfect their maneuvers, we do not let them fall on the hard floor. The social minimum is not a holding bin. It is a trampoline so people can innovate, take risks, and realize their lives' plans. The success of the social minimum is judged by the churn rate that measures how well the institutions and policies have enabled social mobility. Public support depends on that.

It is unfortunate that the phrase social minimum is associated with the welfare state where the primary argument for the social minimum is pity, altruism, or rights for every human for a decent life. There is nothing wrong and in fact something uplifting about these arguments. But, I have proposed a different rationale. A selfinterested (not necessarily selfish or uncaring) rational individual will choose to live 
in a society that has a redistribution policy as specified by the social minimum to enhance her own life's prospects. The social minimum level is indeed difficult to set initially and requires negotiation and compromises among legislators. Once the social minimum levels are agreed upon, it remains stable. Examples are social security and Medicare for elderly that have become widely accepted by the public. The enactment of Medicare came after a contentious debate. Medicare is a model of stability since 1965 .

Maximin remains an ever-changing goal post even though it is relatively easy to identify the least advantaged on income and wealth-though not so easily on the index of primary goods as it requires interpersonal comparison. As soon as the needs of the least advantaged group are met, another previously a bit better off group now becomes the focal point. This is inherently an unstable process until complete equality is achieved. Amongst the aggrieved have included poor, single mothers, those in prison, religious minorities, racial groups- "Black lives matter", addicted to opioids, and more recently non-college educated whites. All these groups do need support. Some group can always be identified as the least advantaged based on how one defines the characteristics. There is always a bottom decile.

The chief purpose of the social minimum is to improve human potential. Investments in programs providing healthcare and education today are likely to improve productivity tomorrow. The earned-income tax credit that motivates people to look for work is supported by both liberals and conservatives. The social minimum does serve as an insurance against the unfortunate calamities of life. In large part, it is inclusive and aims to build cumulative assets for the long term. In a society based on the social minimum, no individual has an upper bound on their achievements and each individual has an opportunity to live a life of dignity with self-respect.

\section{Criticisms of social minimum}

The term "social minimum" is the label I have assigned to the optimal redistribution from the more advantaged state to the less advantaged by an expected utility maximizer. It is not to be confused with the desire to provide basic essential needs for survival that all humans deserve. In Table 2, for example, the social minimum of 30 in the optimal plan may indeed be well above the minimum standard of life. The desire for the social minimum is not driven by benevolence or pity.

The social minimum; instead, is determined by the rational choice of an individual behind the veil of ignorance. The background of the society within which the individual makes a choice amongst alternative systems is assumed to be a democracy with equal liberty and opportunity for all and a well- functioning competitive market economy.

Rawls (1999, page 144) writes "In fact, reasonable risk aversion may be so great, once the enormous hazards of the decision in the original position are fully appreciated, that the utilitarian weighting may be, for practical purposes, so close to the difference principle as to make the simplicity of the latter decisive in its favor." 
I have already discussed that a rational person, in her own soul searching, need not exhibit infinite risk aversion in her choices for decisions under uncertainty. The objection to the maximin principle has been stated by Arrow (1973), Harsanyi (1975), Alexander (1974), and Musgrave (1974), among many others. I would now provide another argument that favors the social minimum over the maximin criterion.

Imagine a few alternative societies that all have a common outcome in the more advantaged state but differ in their outcomes in the less advantaged state. Let us fix $H=100$ as in Table 2 but vary $L$. The maximin rule will require redistribution no matter how large $L$ becomes so long as it is less than $H$. The implication is that the rich must give to the poor even if the poor have become almost rich. A way to think about it is to suppose that the average annual income in the more advantaged state (above the median) is $\$ 100,000$ and the average annual income in the less advantaged state (below the median) is $\$ 50,000$. The maximin rule will require a transfer to achieve the outcome of approximately $\$ 66,666$ in each state. In the social minimum (using log utility), there will be no transfer and thus the final allocation remains unaltered from the initial allocation. If, however, the society has poverty $L=\$ 1000$, then the social minimum will require a substantial redistribution to raise the income level in the less advantaged state to $\$ 25,500$. The social minimum cushions against the blow of the worst calamities and greater equality of opportunity so people can get on their own two feet, but does not permit redistribution indefinitely.

Rawls (1999, page 278) raises a difficulty with the social minimum "how is the social minimum to be selected and adjusted to changing circumstances?" This difficulty arises when the social minimum is determined exogenously based on the social and economic conditions of a society. Usually, the social minimum is the bundle of resources necessary to enable each individual to lead a minimally decent life (Waldron, 1986).

Suppose in our example in Table 2, an average annual income of $\$ 15,000$ is deemed necessary for a minimally decent life. We will call it a society with an exogenously specified social minimum. In such a society, individuals will not have serious discontent if they end up in the less advantaged state. We now modify

Table 3 Distribution of average annual incomes (in thousands of dollars) in four societies

\begin{tabular}{llll}
\hline State & $\begin{array}{l}\text { More advantaged } \\
\text { state }\end{array}$ & $\begin{array}{l}\text { Less advantaged } \\
\text { state }\end{array}$ & $\begin{array}{l}\text { Utility } \\
\text { (rank) }\end{array}$ \\
\hline Alternative & 100 & 10 & \\
Laissez-faire & 40 & 40 & $(4)$ \\
Maximin & 60 & 30 & $(1)$ \\
Social minimum & 90 & 15 & (3) \\
Social minimum (exogenously & & & \\
\hline specified) & & & \\
\hline
\end{tabular}


Table 2 to include such a society in our set of alternatives. Table 3 provides income distributions for the four possible societies.

It is clear from Table 3, that given the parameters of the problem (log utility, leak $=50 \%$ ), the exogenously specified social minimum has a lower expected utility than both the maximin and our social minimum. More importantly, it is a static concept as Waldron (1986) states "there will be no necessary reason for the minimum to rise as the amount of wealth available in society for distribution increases". In contrast both the maximin and our social minimum are principles of distribution; the former being more egalitarian. If the income doubles uniformly, then in both the maximin and our social minimum, optimal redistribution doubles as well. I believe Rawls's objection to social minimum is with the exogenously specified social minimum.

The social minimum is influenced by the presumed inefficiency of redistribution captured by the parameter $\alpha$ in our model. Suppose, over time, inefficiencies are reduced by encouraging work effort and by correcting disparities in opportunities. The arc of improvement of the social minimum point $\mathrm{S}$ in Fig. 1 is towards the point E. The optimal redistribution increases as $\alpha$ decreases and as $\alpha \rightarrow 1$, the social minimum point gets closer to E. The contrast between the more advantaged state and the less advantaged state vanishes; though individual variations in income and wealth might remain. In our example with $\alpha=2$ (leak $=50 \%$ ), the optimal redistribution is 20 units. If the redistribution primarily provides for basic needs, there is a suspicion that such transfers create a permanent dependent class. Provision of education and training, healthcare, access to capital and programs that equip people to become productive and contributing members of society are likely to be more acceptable. In our example with $\alpha=1.5$ (leak $=33.33 \%$ ), the optimal redistribution rises to 28.33 units. The social minimum society may achieve a higher degree of equality without making the least advantaged group as the touchstone of distribution policy.

Optimal redistribution in the social minimum society is based on the expectations of a representative rational individual as viewed from her social and economic position in the more advantaged and the less advantaged states. Once the social minimum is established and institutions are set up to administer it, there is no bound on a specific individual's achievement on income and wealth and position of authority and office. The social minimum society is egalitarian for individuals' equal rights and liberties as it accepts Rawls's first principle of justice. There is also a requirement for fair equality of opportunity. For income and wealth, a reasonable degree of aversion to uncertainty requires that those with higher wealth will share with those with lower wealth though not to the point of equality. The index of primary goods includes health and education and training. Since the social minimum secures a minimum on primary goods, undesirable effects of inequality of income are somewhat tempered. It is an open question whether a rational individual in the original position will actually choose the maximin or a less extreme sharing implied by the social minimum principle. 


\section{Summary}

I have analyzed the choice of a society from the perspective of a rational individual who is behind a "veil of ignorance" (Harsanyi, 1955; Rawls, 1971). The analytical tool of the veil of ignorance prevents one to tilt the structure of the society in one's favor. Therefore, the society one chooses can be regarded as fair or just. Absence of knowledge about one's social and economic position, race, ethnicity, gender or religion is essential in the design of a just society. Though deprived of the knowledge about one's personal circumstances (rich or poor), it is assumed that the individual is aware of the laws of human nature and the workings of democracy and the competitive market system.

Behind the veil, an individual faces a choice problem under uncertainty. A rational individual who is an expected utility maximizer imagines to be in either a more advantaged situation (above median wealth) or a less advantaged situation (below median wealth). The choice problem then reduces to a distribution policy from the more advantaged state to the less advantaged state. Since the whole life is at stake, it is assumed that the individual will be risk averse. Risk aversion is not a condition of rationality but is widely accepted as a trait of human behavior (Bernoulli 1738) in economics and decision theory.

Risk aversion favors a redistribution from the more advantaged state to the less advantaged state as if, behind the veil, one is securing a life insurance of a sort. A rational individual, however, anticipates that the redistribution is not costless. It is known since Edgeworth that a redistribution reduces the total output. Okun (1975) provided several reasons including incentive effects and administrative costs to vividly illustrate that a transfer is carried in a leaky bucket. Thus, for example, to reach $\$ 1$ in the less advantaged state, one must transfer $\$ 2$ from the more advantaged state $($ Leak $=50 \%)$.

The force of the two assumptions-risk aversion and shrinkage in transfer due to incentive effects and inefficiencies-is that the optimal redistribution raises the prospects in the less advantaged state with respect to those in the more advantaged state but not generally to the point of equality. The optimal redistribution ensures a social minimum for the individual.

The social minimum is derived from the principle of the maximization of expected utility and is not exogenously specified (Waldron, 1986). The social minimum society thus reflects the ethics of a self-interested rational individual.

I should note that the social minimum society resembles closely the Rawlsian society with only a small modification. The social minimum is substituted for maximin as the principle of distributive justice. It is quite possible that from a contract theory perspective that Rawls adopts, maximin is a justifiable result. From a decision theory perspective, the social minimum is the logical conclusion for a rational expected utility maximizer.

The social minimum society secures basic liberties for all as free and equal persons. It ensures fair equality of opportunity for health, education, and culture and a free choice of occupation and career progression based on talent and effort. Thus, it fully accepts Ralwsian ideals of equality. The optimal distribution of income and 
wealth in the social minimum society is determined by the maximization of expected utility and not by the maximin principle. The social minimum so obtained is likely to be well above the minimum essential needs (food, health, shelter) —at least in affluent societies. The ideal of the social minimum society is realized if individuals freely cross the boundaries of social and economic positions in their own life times and across generations. The strongly individualistic perspective of expected utility maximization in the choice of a society; as if, asks Mr. James Madison of Virginia, to engage in a reflective soul searching on "what kind of society would I rather have my descendants to inherit?".

Open Access This article is licensed under a Creative Commons Attribution 4.0 International License, which permits use, sharing, adaptation, distribution and reproduction in any medium or format, as long as you give appropriate credit to the original author(s) and the source, provide a link to the Creative Commons licence, and indicate if changes were made. The images or other third party material in this article are included in the article's Creative Commons licence, unless indicated otherwise in a credit line to the material. If material is not included in the article's Creative Commons licence and your intended use is not permitted by statutory regulation or exceeds the permitted use, you will need to obtain permission directly from the copyright holder. To view a copy of this licence, visit http:// creativecommons.org/licenses/by/4.0/.

\section{Appendix: Optimal redistribution}

Suppose an individual expects to be in a high wealth position, $H$, or in a low wealth position, L, with equal chance. The individual is an expected utility maximizer with the utility function strictly increasing and concave in wealth. In the initial situation, expected utility of the individual is:

$$
\frac{1}{2} U(H)+\frac{1}{2} U(L)
$$

The individual commits to a redistribution policy where an amount $\alpha x, \alpha>1$ is transferred from the high wealth position; but, because of the leak due to incentive effects and administrative costs, only the amount $\mathrm{x}$ is received in the less advantaged state.

Expected utility of the individual after the transfer is:

$$
\begin{array}{r}
\frac{1}{2} U(H-\alpha x)+\frac{1}{2} U(L+x) \\
\text { s.t. } x \leq \frac{H-L}{1+\alpha}
\end{array}
$$

At the optimal transfer $x^{*}$, $\frac{U^{\prime}\left(L+x^{*}\right)}{U^{\prime}\left(H-\alpha x^{*}\right)}=\alpha$.

A widely used utility function in economics, psychology and decision analysis is the single parameter power family (Wakker 2008).

For the power family, 
Table 4 Optimal redistributions for varying levels of risk aversion

\begin{tabular}{|c|c|c|c|c|}
\hline & $\begin{array}{l}\text { Optimal } \\
\text { redistribution }\end{array}$ & $\begin{array}{l}\text { More advantaged } \\
\text { state }\end{array}$ & $\begin{array}{l}\text { Less advantaged } \\
\text { state }\end{array}$ & Society \\
\hline$c=1$ (Linear) & 0 & 100 & 10 & Laissez-faire \\
\hline$c=1 / 2($ Cramer $)$ & 10 & 80 & 20 & $\begin{array}{l}\text { Social } \\
\text { minimum }\end{array}$ \\
\hline$c=0$ (Bernoulli) & 20 & 60 & 30 & $\begin{array}{l}\text { Social } \\
\text { minimum }\end{array}$ \\
\hline$c=-1$ & 25 & 50 & 35 & $\begin{array}{l}\text { Social } \\
\text { minimum }\end{array}$ \\
\hline $\begin{array}{l}c=-\infty \\
\quad(\text { Maximin })\end{array}$ & 30 & 40 & 40 & Maximin \\
\hline
\end{tabular}

$$
\begin{array}{r}
U(W)=\frac{W^{c}}{c}, \\
U(W)=\ln (W) \text { if } c=0 .
\end{array}
$$

Notice that the Arrow-Pratt coefficient of relative risk aversion for the power family is constant and is equal to $(1-c)$. Thus, for $c=0$, the Bernoullian utility obtains and for $c=1 / 2$, Cramer utility obtains. Of course, the degree of risk aversion or concavity of the utility function increases as $c$ decreases from 1 (linear utility) to $-\infty$ (maximin utility).

The optimal redistribution $x^{*}$ for the power family with $c<1$ for strict concavity is:

$$
x^{*}=\frac{H-L \alpha^{\frac{1}{1-c}}}{\alpha+\alpha^{\frac{1}{1-c}}}
$$

For Bernoullian log utility $(c=0), x^{*}=\frac{H-\alpha L}{2 \alpha}$, and

for Cramer utility $(c=1 / 2) x^{*}=\frac{H-\alpha^{2} L}{\alpha+\alpha^{2}}$.

For our example in Table 2, $H=100, L=10, \alpha=2$, optimal redistributions for alternative assumptions on the degree of risk aversion $\mathrm{c}$ are given in Table 4 .

The choice of a society is justified by a common framework of the maximization of expected utility. Laissez-faire is optimal under the assumption of risk neutrality $(c=1)$. Maximin is optimal under extreme risk aversion $(c=-\infty)$. Social minimum society entails redistribution but not to the point of equality.

\section{References}

Alexander, S. (1974). Social evaluation through notional choice. The Quarterly Journal of Economics, 88(4), 597-634.

Arrow, K. J. (1971). Essays in the theory of risk bearing. Apopka: Markham Publishing Company.

Arrow, K. J. (1973). Some ordinalist-utilitarian notes on Rawls's theory of justice. The Journal of Philosophy LXX, 9, 245-263. 
Bentham, J. (1789). The Principles of morals and legislation. London: Oxford University Press.

Bernoulli, D. (1738). Exposition of a new theory on the measurement of risk. Econometrica, 22(1), 23-36. (Original article published in Latin in Papers of the Imperial Academy of Sciences in Petersburg, vol. v, 175-192,1738).

Edgeworth, F. Y. (1881). Mathematical psychics. London: Kegan Paul.

Friedman, M. (1980). Free to choose. London: Harcourt Inc.

Harsanyi, J. C. (1955). Cardinal welfare, individualistic ethics, and interpersonal comparisons of utility. Journal of Political Economy LXIII, 26, 309-321.

Harsanyi, J. C. (1975). Can the maximin principle serve as a basis for morality? A critique of John Rawls's theory. Journal of Political Economy, 69(2), 594-606.

Hart, H. L. A. (1973). Rawls on liberty and its priority. Chicago Law Review, 40(3), 534-555.

Keeney, R. L., \& Raiffa, H. (1976). Decisions with multiple objectives. Berlin: Wiley.

Keynes, J. M. (1921). A treatise on probability. London: Macmillan \& Co.

Knight, F. H. (1921). Risk, uncertainty, and profit. New York: Houghton Miffin.

Marshall, A. (1907). Principles of economics. London: MacMillan.

Meade, J. E. (1964). Efficiency, equality, and the ownership of property. London: Allen and Unwin.

Mill, J. S. (1859). On liberty. London: John Parker.

Musgrave, R. A. (1974). Maximin, uncertainty, and the leisure trade-off. The Quarterly Journal of Economics, 88(4), 625-632.

Nozick, R. (1974). Anarchy, state, and utopia. New York: Basic Books.

Okun, A. M. (1975). Equality and efficiency. Washington, DC: Brookings.

Rawls, J. (1971). A theory of justice. Cambridge: Harvard University Press.

Rawls, J. (1999). A theory of justice, Revised Edition. Cambridge: Harvard University Press.

Rawls, J. (2001). Justice as fairness. Cambridge: Harvard University Press.

Samuelson, P. A., \& Nordhaus, W. D. (2010). Economics. New York: McGraw Hill.

Sarin, R. K. (1982). Strength of preference and risky choice. Operations Research, 30(5), 982-997.

Sarin, R. K., \& Wakker, P. P. (1992). A simple axiomatization of nonadditive expected utility. Econometrica, 60(6), 1255-1272.

Savage, L. J. (1954). The Foundations of Statistics. New York: Wiley.

Schmeidler, D. (1989). Subjective probability and expected utility without additivity. Econometrica, 57(3), 571-587.

Smith, A. (1759). The Theory of Moral Sentiments. In: Raphael DD and Macfie AL (eds), Oxford: Oxford University Press.

Smith, A. (1776). Wealth of nations. London: Springer.

Stigler, G. J., \& Becker, G. S. (1977). De gustibus non est disputandum. American Economic Review, 67(2), 76-90.

von Neumann, J., \& Morgenstern, O. (1947). Theory of games and economic behavior. Princeton: Princeton University Press.

Wakker, P. P. (2008). Explaining the characteristics of the power (CRRA) utility family. Health Economics, 17(2), 1329-1344.

Waldron, J. (1986). John Rawls and the social minimum. Journal of Applied Philosophy, 3(1), 21-33.

Publisher's Note Springer Nature remains neutral with regard to jurisdictional claims in published maps and institutional affiliations. 